\title{
Mentoring, Training and Support to Global Health Innovators: A Scoping Review
}

\author{
Dan-Bi Cho ${ }^{1}$, Donald Cole ${ }^{2,3}$, Ken Simiyu ${ }^{4}$, Winnie Luong ${ }^{4} \&$ Vic Neufeld ${ }^{3,5}$ \\ ${ }^{1}$ Global Health Division, Dalla Lana School of Public Health, University of Toronto, Toronto, ON, Canada \\ ${ }^{2}$ Institute for Global Health Equity \& Innovation \& Global Health Division, Dalla Lana School of Public Health, \\ University of Toronto, Toronto, ON, Canada \\ ${ }^{3}$ Canadian Coalition for Global Health Research, Ottawa, ON, Canada \\ ${ }^{4}$ Grand Challenges Canada at the Sandra Rotman Centre, Toronto, ON, Canada \\ ${ }^{5}$ Department of Clinical Epidemiology \& Biostatistics, McMaster University, Hamilton, ON, Canada \\ Correspondence: Dan-Bi Cho, Department of Public Health Sciences \& Global Health Division, Dalla Lana \\ School of Public Health, Health Sciences Building, 155 College Street Suite 400, University of Toronto, Toronto, \\ ON, M5T 3M7, Canada. Tel: 647-454-8192. E-mail: danbi.cho@mail.utoronto.ca
}

\author{
Received: May 27, 2013 Accepted: June 27, 2013 Online Published: June 28, 2013 \\ doi:10.5539/gjhs.v5n5p162 URL: http://dx.doi.org/10.5539/gjhs.v5n5p162
}

Grand Challenges Canada Summer Student Placement Program funding to Cho, D-B.

\begin{abstract}
Global health innovators must navigate substantial complexities to successfully develop, implement and sustain global health innovations with impact through application of an Integrated Innovation ${ }^{\mathrm{TM}}$ approach. We sought to examine the nature of the literature and evidence around mentoring, training and support of global health innovators. We conducted a scoping review searching eight databases with terms capturing different kinds of innovation and support. Assessment of relevance and mapping was completed by two reviewers, with interpretation by the review team. Twenty-eight relevant papers provided perspectives on fostering global health innovators and innovation. Fifteen included empirical data on supports to global health innovators involving a wide range of innovators. Eight included documentation of outcomes but without designs to determine effectiveness. The diverse mentoring, training and support activities included: business incubators, support organizations and centres for entrepreneurship, technology transfer and intellectual property management, internship programs for business skill development, initiatives to bridge industry and researchers, and platforms for South-led innovation for global health. We propose the cultivation of a pipeline of global health innovators to increase the number of appropriate, sustainable innovations with impact in global health. Further empirical work on how to effectively support global health innovators is needed.
\end{abstract}

Keywords: developing countries, technological innovations, organizational innovation, mentors, training support

\section{Introduction}

Global public health is being impacted by ongoing innovation in a myriad of ways that may or may not promote health equity (Cozzens \& Kaplinsky, 2009), depending on the nature of the innovation's development and its scale-up (McGahan, 2012). Health innovations such as new vaccines, diagnostic devices, product development partnerships and preventive and therapeutic interventions are being rolled out in low- and middle- income countries (LMICs), stimulating growth in their economies (Gardner, Acharya, \& Yach, 2007; Yamey, 2012; Morel et al., 2005 ). Innovation for global health can mean "...to [take] up novel ideas, inventions or processes and [apply] them to achieve improved health and greater health equity" (Matlin, 2008, p. 13). Global health innovation can be facilitated through various approaches such as venture funding for biotechnology, public-private partnerships, and novel models of health service delivery. However, these mechanisms are most often focused on various segments within an innovation cycle - either discovery (involving basic research), development (clinical development), or delivery (ensuring end users receive products) (Matlin, 2008). Other 
approaches to global health innovation include the work of the Bill and Melinda Gates Foundation, which is focused on developing and propelling technological innovation to tackle global health challenges.

However, technological, business, and social sectors are highly influenced by the complexities of international relationships, national innovation systems, and the general national environment. Each can affect the discovery, development, effective implementation and equitable adoption of innovations which impact health (Matlin, 2008; McCannon et al., 2007). This illustrates the significance of an Integrated Innovation ${ }^{\mathrm{TM}}$ (scientific/technological, business, social innovation) approach to global health that aims to support the entire process of innovation from beginning to end, in light of these factors. Recently, there has been a major push to conceive of health innovation as a multi-sectoral process, reflected through institutional funding and training (e.g. University of Toronto Institute of Global Health Equity and Innovation, National Institutes of Health Framework Programs for Global Health Innovation) (University of Toronto, 2013; National Institutes of Health Fogarty International Centre, 2012), and nonprofit organizations (e.g. PATH) (PATH, 2013) and higher level policy discussions within European organizations (Battams et al., 2011). Young innovators in both high income countries (HICs) and low and middle income countries (LMICs), who aim to achieve equitable health outcomes through innovation, must receive the proper mentorship, training and support so that they are better able to navigate complexities and mitigate gaps in skills, knowledge or resources during the innovation process. A vast literature speaks to the need for and provides specific examples of mentorship, training and support for innovators in different health sectors - clinicians in academic medicine, public health, academic entrepreneurs, etc. (Manabe et al., 2009; Mahayosnand \& Stigler, 1999; Jackson et al., 2003). Challenges faced by innovators are often focused on scientists failing to cross the innovation-to-commercialization gap (the "Valley of Death") due to their lack of understanding of commercialization, entrepreneurship, product development, market value and general business concepts (Markham, 2002).

In the field of global health, young innovators are likely to face similar challenges, compounded by the complexities of innovation processes in different national innovation and public health systems. The Global Forum for Health Research aims to support strengthening of LMIC research and innovation systems for health, focusing on social, scientific/technological and business innovation research to impact on global health. The Canadian Coalition for Global Health Research (CCGHR), a network of global health researchers, organizations, and students, has expertise in mentorship, leadership and capacity development in global health research more generally. Grand Challenges Canada ${ }^{\mathrm{TM}}$ (GCC), funded by the government of Canada, is a non-profit organization that supports global health innovators in LMICs as well as Canada. However, we were unable to identify any sources that systematically examined requirements for and gaps in mentorship, training and support for global health innovators across the three Integrated Innovation ${ }^{\mathrm{TM}}$ sectors.

Hence, we conducted this scoping review to systematically scan the evidence for mentorship, training and support of innovators who would take an Integrated Innovation ${ }^{\mathrm{TM}}$ to global health innovation. We used GCC's organizational process and innovation funding cycle for global health innovators as a case example to which we could apply our review findings.

\section{Methods}

We chose a scoping review approach given our desire: (1) to map the extent, range and nature of research activity; (2) to help determine whether a full systematic review would be valuable and feasible; (3) to summarize and disseminate findings for an audience of innovators, mentors and funders; and (4) to identify research gaps in the current literature (Arksey \& O’Malley, 2005). 


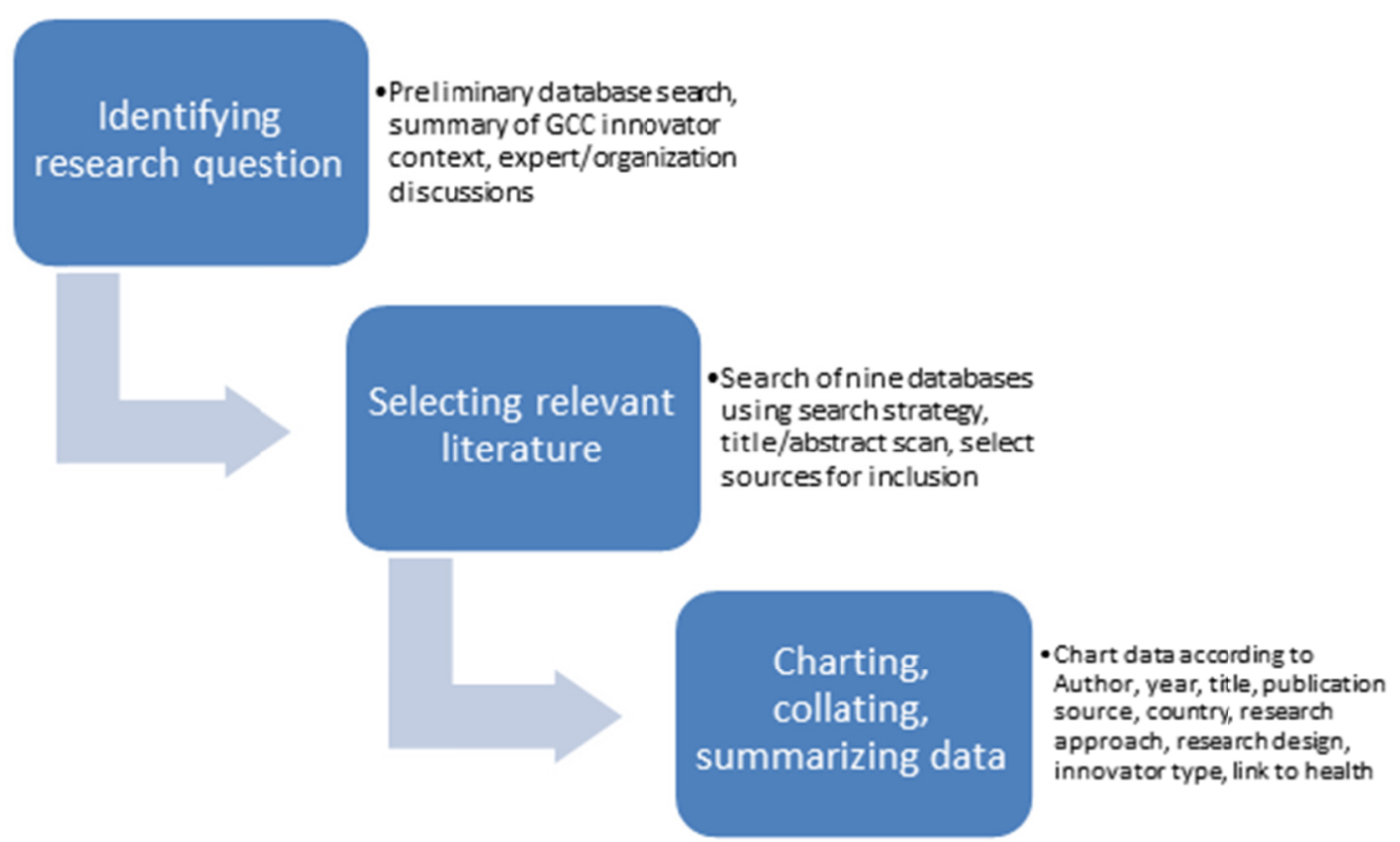

Figure 1. Methods schematic

Our review consisted of three phases between May and August 2012: (1) identifying the research questions, (2) selecting relevant literature and (3) charting, collating, summarizing and interpreting our findings (Figure 1).

\subsection{Identifying Research Questions}

To improve our review's applicability to our case of interest, we briefly summarized information on GCC Stars in Global Health Round 1 and 2 grantees $(\mathrm{n}=34)$.

Table 1. Grand Challenges Canada (GCC) ${ }^{\mathrm{TM}}$ stars in global health program

"Stars in Global Health" ideally demonstrate the coordination of scientific/ technological, business and social innovation to
propel a bold idea that will have an impact in global health. This approach, called Integrated Innovation TM, recognizes that
scientific/technological innovations for health are more likely to be scaled up and implemented with impact and
sustainability, if they are developed with social and business innovations from the onset (Grand Challenges Canada, 2010).
The program adopts an 'innovation-push' approach (Malinen et al., 2008) funding new investigators from Canada or LMICs
to develop, modify and validate their innovation through Phase I proof of concept grants.
The majority of Phase I grantees in the first two rounds (n=19 in round $1, \mathrm{n}=15$ in round 2 ) were concentrated in science and
academic research and affiliated with academic institutions. In round 1, two had experience in the corporate sector related to
research and development and consulting and one mentioned formulating plans for commercialization links as part of the
project. In round two, two of fifteen grantees had a business educational background (MBA) and five had some
business/corporate experience in research and development consulting, partnering with joint ventures, director of program
managing innovations, MBA background. Types of global health innovations have included: point of care diagnostic devices,
the use of mobile health technologies to decrease maternal and child deaths, vaccine development and energy-efficient water
purification systems.
Grantees identify a mentor on their project for support and guidance. Most Stars in Global Health grantees to date have been
linked to mentors by background or expertise relevant to project components. Subsequently, these mentors should support
grantees to pursue Phase II scale up grants by getting 'buy-in' from for-profit and not-for-profit partners to implement high
quality and affordable innovations in alignment with local and regional social contexts in LMICs. For this stage, GCC offers
online resources to help respond to the challenges that may arise when taking a global health innovation to scale and
implementation.


As shown in Table 1, the 34 Stars in Global Health projects had been under way between 9-12 months. The grantees were relatively young in their careers as eligibility to participate in the first two rounds was restricted to those within ten years of attainment of their latest degree and most were from science/technological, academic backgrounds. Few mentors or mentees had business related experience, though a number had social innovation experience in partnerships (see http://www.grandchallenges.ca for further details).

The review team included experience in commercialization of science-based health innovations in LMICs, strategy and operations analysis, and coordination of the Stars in Global Health program, all from GCC, along with global health research capacity development in LMICs. An MPH student specializing in health promotion and global health led discussions of the grantee context and GCC needs to formulate three questions for exploration in this scoping review:

1) What is the nature of evidence around mentorship, training and support for innovators in global health?

2) How is the Integrated Innovation ${ }^{\mathrm{TM}}$ approach in global health being reflected in the mentorship, training and support for innovators? And

3) What type of initiatives in mentorship, training and support for innovators are applicable to the GCC Stars in Global Health program and implementable in its structure and context?

\subsection{Identifying Relevant Papers}

Preliminary literature searches helped formulate a search strategy that encompassed the main concepts, appropriate terms and the most relevant databases.

As seen in Table 2, keywords within each topic category were combined with OR. Across topic categories, terms were combined with AND. The search strategy was piloted and refined during consultations with an information specialist, tested in various databases to ensure that relevant results were appearing. Eight electronic databases, chosen for their multidisciplinary focus and relevance to the research questions, were systematically searched for their earliest available year to June 2012 (see Supplementary File Table 1 for details): Medline, BioMed Central, Business Source Premier, Embase, Scopus, Web of Science, Social Sciences Abstracts, and ProQuest.

Table 2. Keyword strategy used in searches

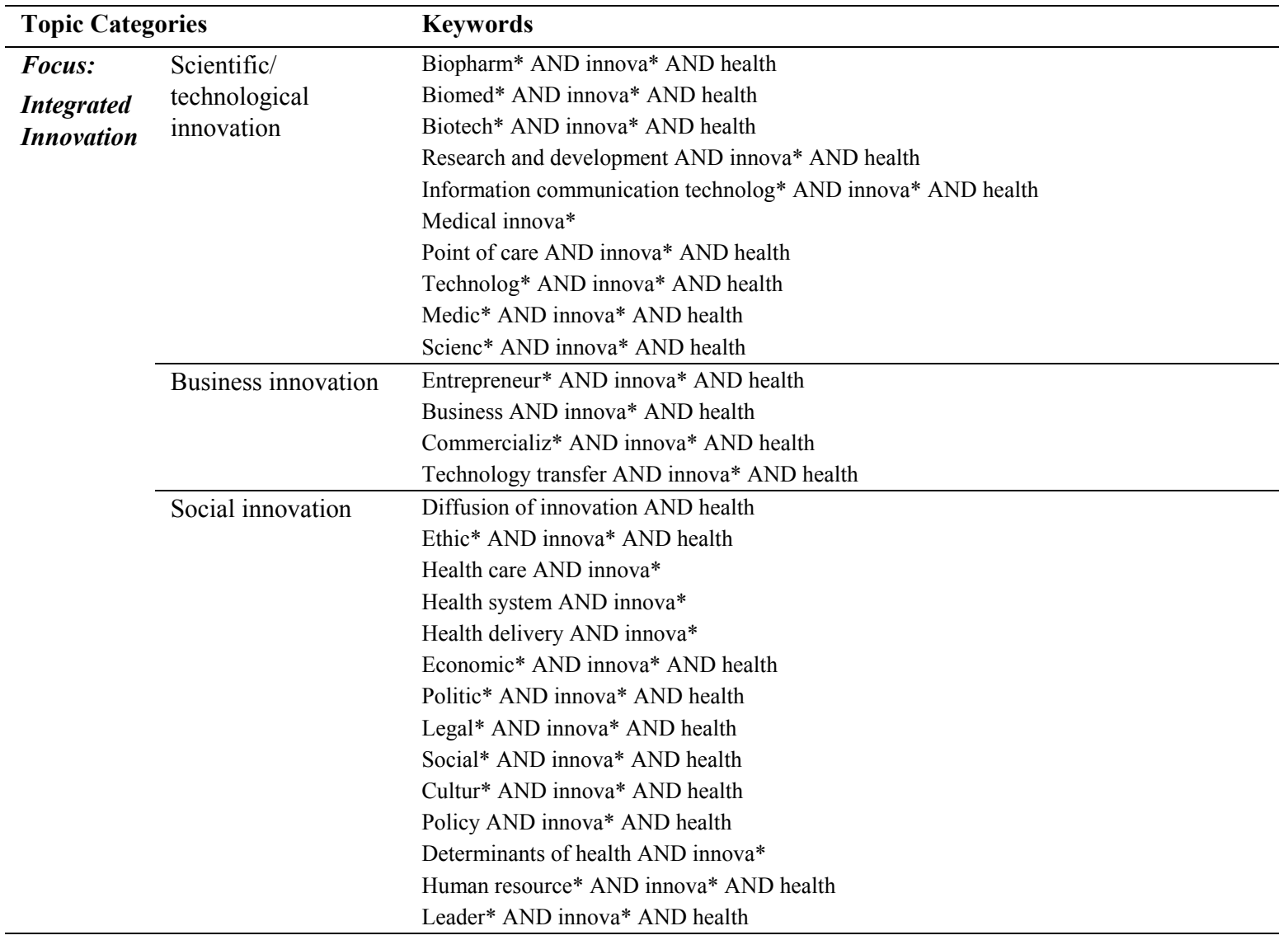




\begin{tabular}{ll}
\hline Topic Categories & Keywords \\
\hline & Social change AND innova* AND health \\
& Equity AND innova* AND health \\
& Govern* AND innova* AND health \\
& Implement* science AND health \\
& Translation* science AND health \\
& "Scaling up" AND health \\
& "Scale up" AND health \\
& "Scaling-up" AND health \\
& "Scale-up" AND health \\
\hline What: & Advisor \\
Training, support, mentorship & Mentor* \\
& Mentee* \\
Supervis* & Teach* \\
Support* \\
Train* \\
Coach* \\
Innovator* \\
Researcher* \\
Scientist* \\
Clinician* \\
Professional* (Lawyers, Vets) \\
Practitioner* \\
Health professionals (Physicians, Nurses, Naturopathic doctors, Chiropractors) \\
Students (MPH, MBA) \\
Investigators (PhD) \\
\hline
\end{tabular}

\subsection{Paper Selection}

Retrieved English titles and abstracts were independently reviewed by one team member for initial relevance related to innovation, health, and mentorship/support/ training. A five percent random sub-sample was reviewed by a second team member. Raw inter-rater agreement on relevance was $77 \%$. Formal inclusion and exclusion criteria were devised at this stage, and these two researchers independently reviewed each title and abstract for relevance, with resolution of disagreements by consensus. Major reasons for exclusion were: (1) no focus on health; (2) no focus on innovation; (3) no mention of type, potential, or need for support/training/mentorship of innovators. Included papers that were accessible by University of Toronto libraries were reviewed in full. Reference lists from papers included for full review were searched, and relevant papers to the research questions were also retrieved. Mendeley software was used for data management.

\subsection{Mapping the Data}

The following information was extracted from each paper: author(s), year, title, publication source, country, paper type, type of stakeholder(s), link to Integrated Innovation ${ }^{\mathrm{TM}}$ approach, and type of support/training/mentorship, either needs described or/and specific activities. The review leads held meetings to discuss extracted data and to synthesize our findings, following an inductive approach.

\section{Results}

The final search strategy generated 1535 titles and abstracts. Following initial title and abstract reviews and hand-searching of reference lists, 28 papers were judged relevant in this scoping review (full details in supplementary file).

\subsection{What is the Nature of Evidence around Mentorship, Training and Support for Innovators in Global Health?}

Most papers were published recently, with half $(n=14)$ published in 2010. Eighteen (64\%) were based in LMICs and the remainder in the USA and Canada $(\mathrm{n}=10)$. Most discussed all three of scientific/technology, business and, social innovation $(\mathrm{n}=23)$, with the rest $(\mathrm{n}=5)$ not including social innovation in a substantive manner. Four only discussed needs, ten focused on activities, half covered both. Nine provided perspectives (commentaries, editorials, etc.), four described programs of different kinds and 15 (56\%) took some kind of empiric approach.

Eight of the latter papers included information on outcomes, including a promising framework for evaluation (Allen et al., 2010). Some reported students trained (Oden et al., 2010), university-industry collaborations initiated 
(Rezaie et al., 2008), companies developed (Chakma et al., 2010), and locally relevant technologies translated (Shah et al., 2010). One (Oden et al., 2010) reported a specific training outcome: $95 \%$ alumni commented that the program changed/modified their career plans to focus on global health medicine, research, and/or policy. Unfortunately, none provided sufficient evaluation data in comparative designs to determine the effectiveness of support, training, or mentorship activities in global health innovation.

\subsection{How is an Integrated Innovation ${ }^{T M}$ Approach in Global Health Being Reflected in the Mentorship, Training and Support for Innovators?}

Drawing primarily on the empirical studies which included activities oriented by all three types of innovation $(\mathrm{n}=15)$ we found a wide variety of relevant activities, half with multiple stakeholders, reflecting innovation system perspectives.

Table 3. Empirical papers relevant to mentoring, training and supporting global health innovators with an Integrated Innovation ${ }^{\mathrm{TM}}$ approach

\begin{tabular}{|c|c|c|c|}
\hline $\begin{array}{l}\text { First } \\
\text { Author } \\
\text { (date) }\end{array}$ & $\begin{array}{l}\text { Country } \\
\text { (ies) }\end{array}$ & $\begin{array}{l}\text { Type (s) of } \\
\text { stake-hold } \\
\text { er(s) }\end{array}$ & $\begin{array}{l}\text { Support/Training/Mentorship } \\
(\mathrm{N}=\text { Needs, } \mathrm{A}=\text { Activities, } \mathrm{O}=\text { Outcomes })\end{array}$ \\
\hline $\begin{array}{l}\text { Al-Bader et } \\
\text { al. (2009) }\end{array}$ & $\begin{array}{l}\text { South } \\
\text { Africa }\end{array}$ & Government & $\begin{array}{l}\text { Improving skills gap } \\
\text { Training of scientists in business and entrepreneurial skills } \\
\text { Mentorship from business community with health biotechnology experience } \\
\text { Hellfire internship program to develop business and specialist skills } \\
\text { Judged 'successful' but no longer operational }\end{array}$ \\
\hline $\begin{array}{l}\text { Al-Bader et } \\
\text { al. }(2010 a)\end{array}$ & $\begin{array}{l}\text { Ghana, } \\
\text { Rwanda, } \\
\text { Tanzania, } \\
\text { Uganda }\end{array}$ & $\begin{array}{l}\text { Government, } \\
\text { research } \\
\text { institutes, } \\
\text { university, } \\
\text { private sector }\end{array}$ & $\begin{array}{l}\text { Platforms to enable access to financing } \\
\text { Trust between stakeholder interactions } \\
\text { Local insight, priorities and tacit knowledge } \\
\text { Policies and strategies around innovation } \\
\text { Cluster-building, business incubation } \\
\text { Innovation platform to bring together science, business, capital partnerships and collaboration }\end{array}$ \\
\hline $\begin{array}{l}\text { Al-Bader et } \\
\text { al. }(2010 b)\end{array}$ & Ghana & $\begin{array}{l}\text { Government, } \\
\text { research } \\
\text { institutes/ } \\
\text { Universities, } \\
\text { private } \\
\text { sector, NGOs } \\
\text { and donors }\end{array}$ & $\begin{array}{l}\text { Business knowledge in health sectors } \\
\text { Links to industry and local stakeholders (i.e. traditional healers) } \\
\text { Regulatory harmonization } \\
\text { Intellectual property regulation } \\
\text { R\&D and health research spending } \\
\text { Product development understanding } \\
\text { Trust in stakeholder interactions } \\
\text { Knowledge of local market } \\
\text { Linking science and technology to health objectives } \\
\text { Technology Consultancy Centre } \\
\text { EMPRETEC entrepreneurship support organization } \\
\text { National Board of Small Scale Industries } \\
\text { GRATIS public agency for tech development and transfer } \\
\text { TechnoServe entrepreneurship support organization } \\
\text { Working group on health innovation }\end{array}$ \\
\hline $\begin{array}{l}\text { Allen et al. } \\
(2010)\end{array}$ & Tanzania & $\begin{array}{l}\text { Researcher } \\
\text { observing } \\
\text { private sector }\end{array}$ & $\begin{array}{l}\text { Framework for health research in LMIC settings } \\
\text { Combination of social sciences research methods and business model aspects of social entrepreneurship } \\
\text { Evaluation of framework by examining achievement of milestones }\end{array}$ \\
\hline $\begin{array}{l}\text { Chakma et } \\
\text { al. }(2010)\end{array}$ & $\begin{array}{l}\text { South } \\
\text { Africa }\end{array}$ & $\begin{array}{l}\text { Government, } \\
\text { private sector }\end{array}$ & $\begin{array}{l}\text { "Soft services" such as hands-on networking and mentorship } \\
\text { Pairing scientists with entrepreneurs } \\
\text { Support from early to late-stage function of innovation development and commercialization } \\
\text { Publicly funded virtual incubator to develop life science ventures } \\
\text { Provide business advisory services, network contacts } \\
\text { Serve as intermediary between granting agencies and investors } \\
\text { Focus on mentoring early-stage entrepreneurs } \\
\text { Hellfire internship program for young scientists to create a pipeline of scientist entrepreneurs for } \\
\text { start-ups } \\
\text { Development of companies, lessons learned }\end{array}$ \\
\hline $\begin{array}{l}\text { Frew et al. } \\
(2007)\end{array}$ & India & $\begin{array}{l}\text { Government, } \\
\text { research } \\
\text { institutes, } \\
\text { private } \\
\text { sector, NGOs } \\
\text { and donors }\end{array}$ & $\begin{array}{l}\text { Government policies and support, expertise of private sector for early-stage product development } \\
\text { Targeted funding approach Improved public health infrastructure } \\
\text { Incentives for private firms to develop innovative distribution strategies } \\
\text { Recommended based on study: } \\
\text { Single agency to provide science mentoring } \\
\text { Local collaborations between R\&D and research institutions } \\
\text { Access to government-sponsored research funds } \\
\text { Focus on developing innovations to address local health needs }\end{array}$ \\
\hline
\end{tabular}




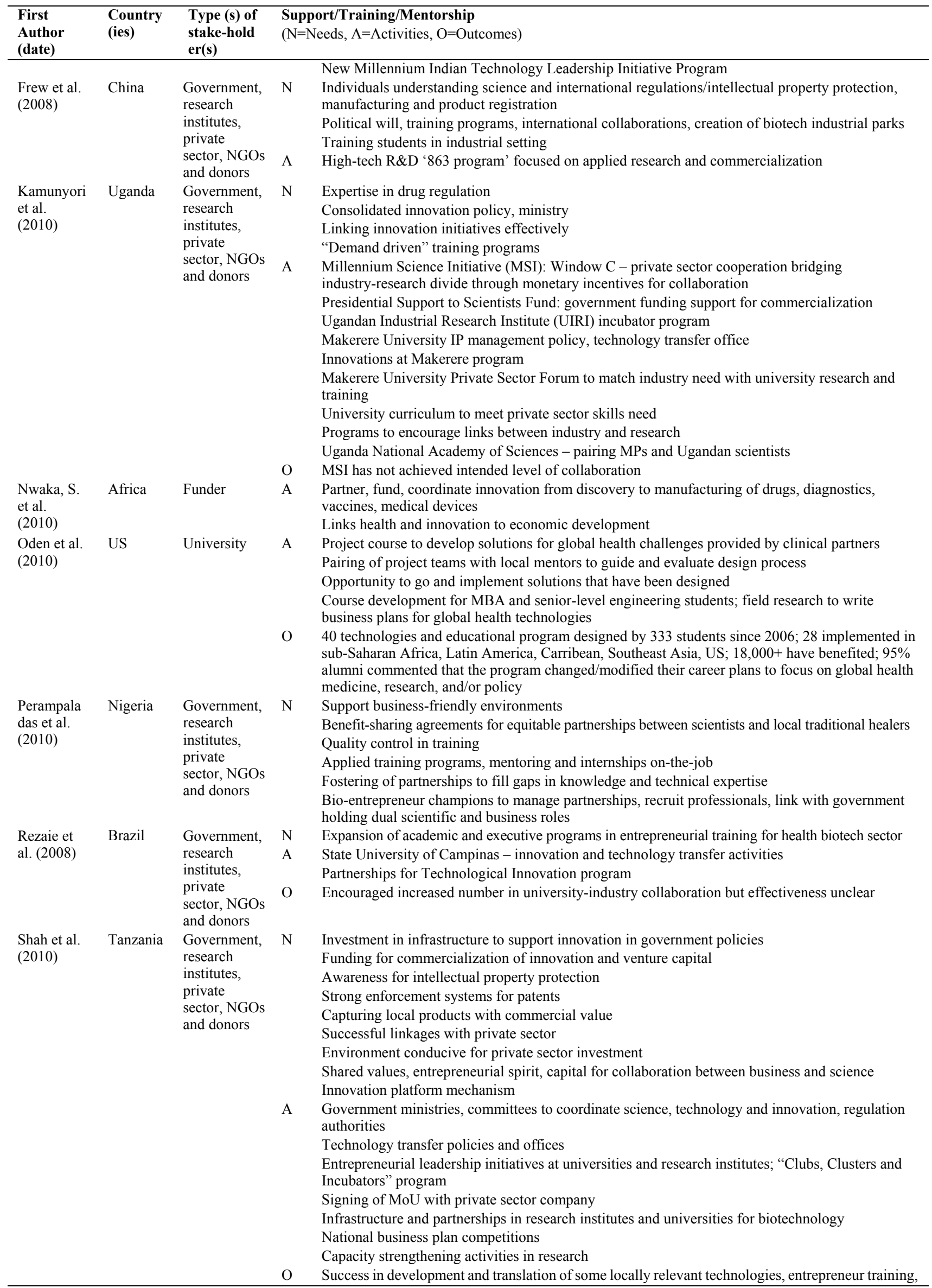




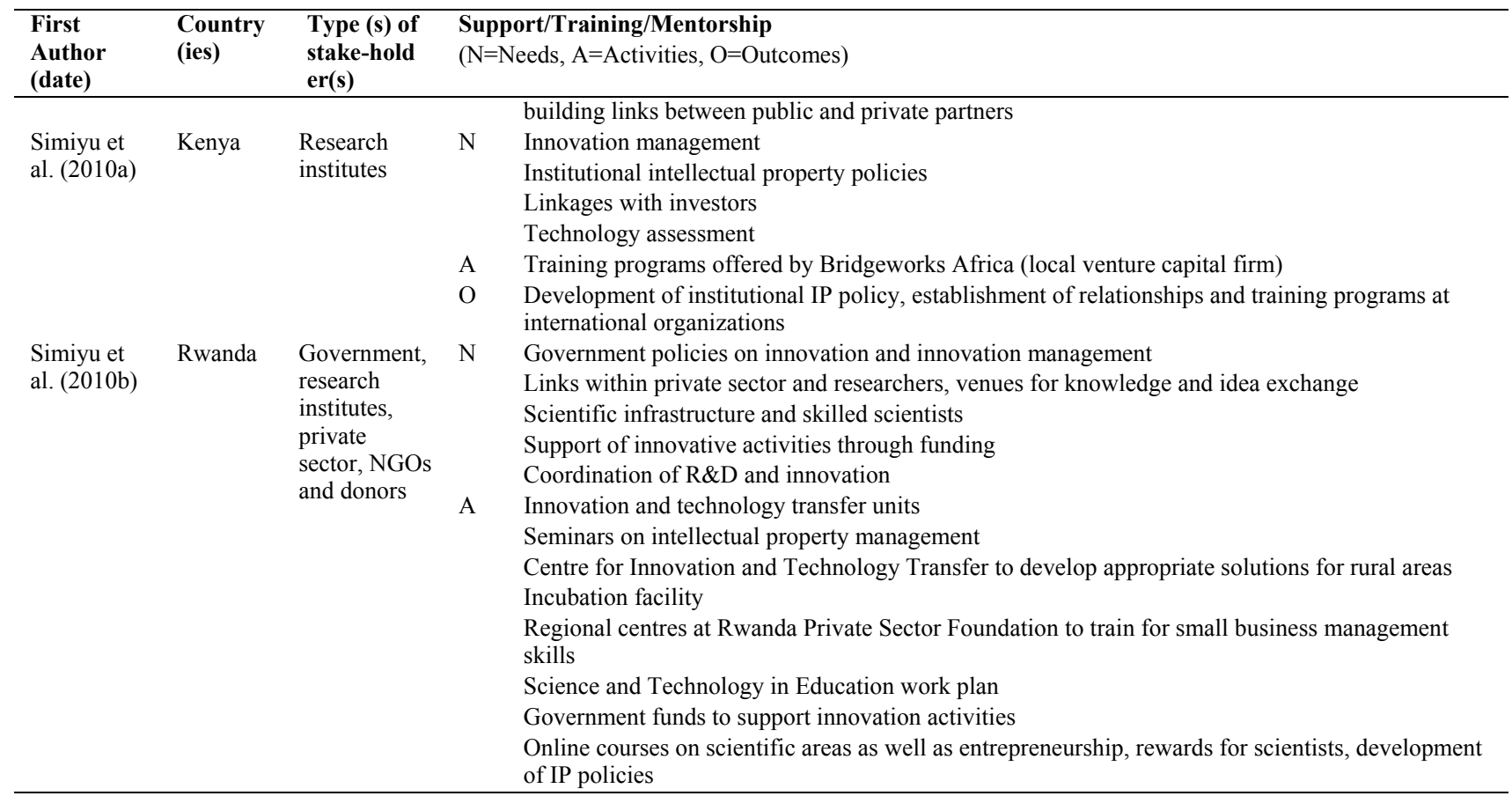

As outlined in Table 3, the specific activities in LMICs to support, train and mentor innovators for health innovation aimed to fill identified needs included: business incubators, support organizations and centres for entrepreneurship, technology transfer and intellectual property management, internship programs for business skill development, government funding, and initiatives to bridge industry and researchers, and platforms for South-led innovation for global health. There was a heavy emphasis on supporting, training and mentorship of innovators in the science-business knowledge and resource gap. The focus was primarily on commercialization for product-based health innovation with little explicit mention of training to understand the social contexts in which innovations are to be implemented.

\section{Discussion}

Given the newness of the global health innovation field, our mapping found papers on perspectives, new programs, and a range of activities to support global health innovators but limited empirical work to inform training, mentoring and support practice. Literature on mentorship in global health clinical research (Shah et al., 2011) and academic medicine (Nelson et al., 2012) are focused on helping trainees achieve research productivity, career development or appropriate conduct in global settings. These important objectives of mentorship need to be complemented for global health innovators by helping trainees understand the cycle of innovation and the social contexts in which innovations will be discovered, developed, scaled up, deployed, and sustained.

\subsection{System Level}

Papers identified in this scoping review did indicate a number of mechanisms by which support, training and mentorship of global health innovators may be facilitated with the involvement of micro to macro level stakeholders. In LMICs, the identified mentorship, training, and support structures were highly focused on capacity building within the innovation system itself so that innovation might be better facilitated. A good example of a program (unfortunately without evaluation data) is the African Network for Drugs and Diagnostics (Mboya-Okeyo, Ridley, \& Nwaka, 2009). It enables African-led research and innovation for discovery, development and delivery to treat diseases affecting Africa (science/technology), with a focus on translation of innovations (social) and also aims to attract commercial investments and collaborations between South-South and North-South partners (business).

\subsection{Institution Level}

Responding to Hotez and colleagues' (2005) call for public health institutions to train students in appropriate technology, and to ensure core competencies are reflective of technical and "real world" skills for product development and use, is Northwestern University's tripartite collaborative model (Palamountain et al., 2010) in which diagnostic companies donate health technology innovations, and students from schools of engineering, 
business, medicine and social science adapt and market them for LMIC settings. Oden and colleagues (2010) provided initial empiric data on the role of university-based training effort which modified students' future career plans.

\subsection{Role of Funders}

Beyond the funding primarily for global health innovation activities (Nwaka et al., 2010), funders of innovators training in an Integrated Innovation ${ }^{\mathrm{TM}}$ approach have a range of opportunities. The National Institutes of Health Fogarty International Center's Framework Programs for Global Health Innovation is one example (National Institutes of Health Fogarty International Center, 2012). This program supports US and LMIC institutions to develop interdisciplinary, postdoctoral training programs for global health innovation products, processes and policies. Funder- sponsored opportunities offered to grantees have included: online websites and web sources to foster collaboration, providing opportunities to discuss with previous grantees, independent consultation, workshops, trainee development programs and curricula, establishing partnerships between industry, government, non-government, academic organizations, virtual forums for collaborations, and "knowledge broker" approaches.

\subsection{Application to GCC Stars in Global Health Program}

The approaches we uncovered in our review may apply at different stages of the innovation process, enabling discovery, development, implementation and sustainability of innovations for greater impact on global health, Mentoring, training and support could be conceptualized holistically from start to finish throughout the process of global health innovation. We applied approaches uncovered in our review to the phases of GCC's innovation cycle (see Figure 2) which build on GCC's current online proposal development resource, that is updated frequently with relevant content, and its LinkedIn group to facilitate collaboration.

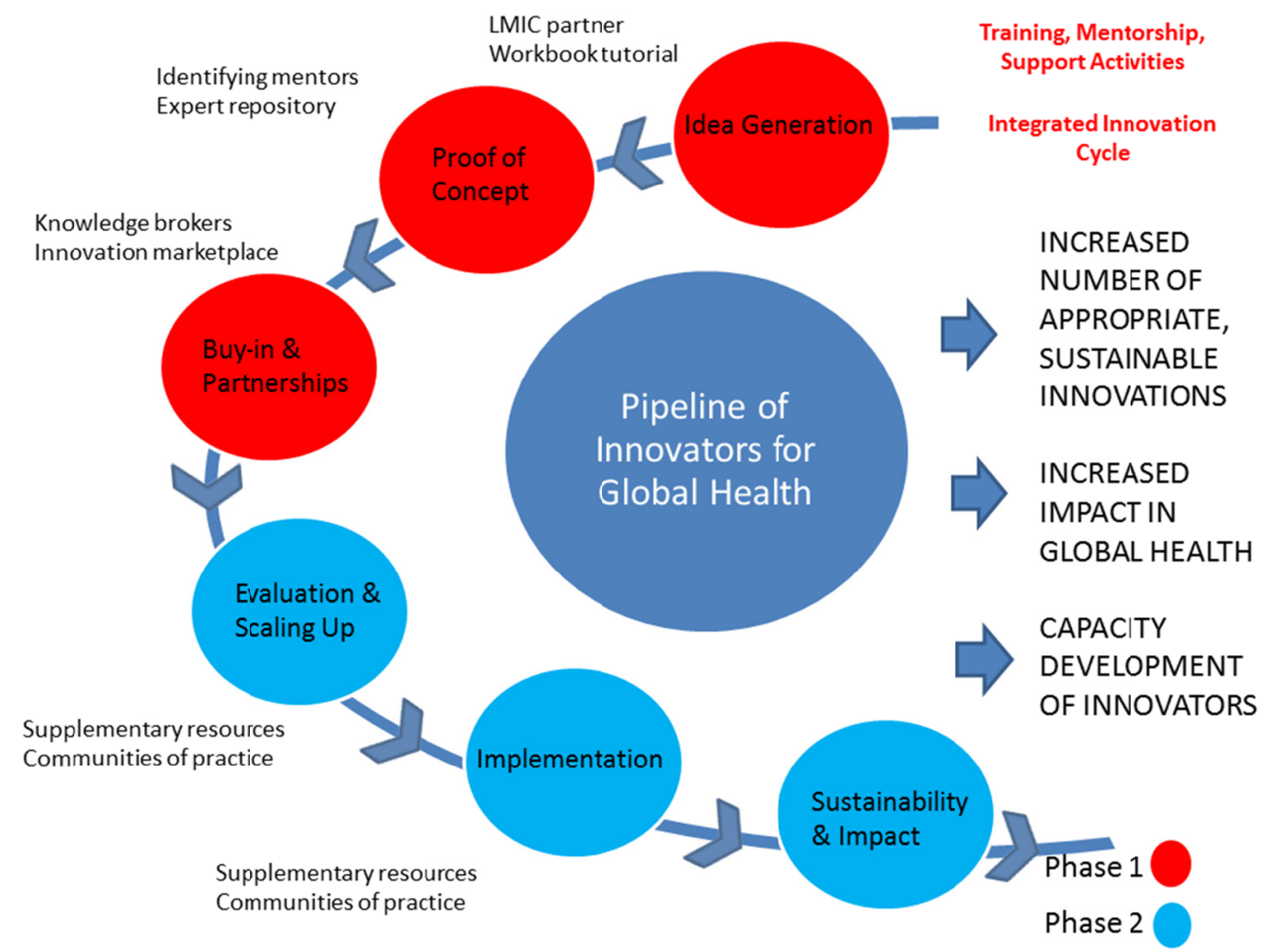

Figure 2. Pipeline of innovators for global health

In Phase I, GCC (and other global health innovation funders) could focus on partnerships and skill-building whereby grantees ground themselves in how their projects should be defined and conceptualized through an Integrated Innovation ${ }^{\mathrm{TM}}$ approach. Partnering to identify LMIC needs, context and partnerships and identifying other mentors who are not in the same field of expertise as the innovator, may fill gaps when undertaking proof 
of concept studies. Milestones in reporting for mentorship activities could be elicited. A repository of experts, particularly with business and social innovation acumen (as these areas of expertise seem to be lacking the most) and who have experience in global health contexts, could be built for grantees to contact if needed. Knowledge brokers could act as "middlemen" to guide and mentor grantees on bridging the challenges in taking an innovation to a specific commercial market, as well as to help with building core skills (e.g. writing a business plan). Innovations that merit Phase II funding could be showcased as part of an innovation marketplace for potential partners and investors, which would help grantees gain skills in presenting, making elevator pitches, networking, etc.

In Phase II, supplementary sources addressing implementation science, translational science, product development partnerships (Rabin et al., 2008; Yamey, 2011) could be added to the online proposal development resource, which would supplement the entrepreneurship skillsets being built to help fill in knowledge and practice gaps around evaluation, scaling up, and implementation. Communities of practice, which have been utilized widely in business and health sectors (Li et al., 2009), could be facilitated amongst these innovators to share tacit knowledge and learning. The partnerships and networks built through interactions amongst the innovators, potential partners and investors, as well as the knowledge and skills gained through the training, mentorship and support activities could enable capacity development of innovators as they move to achieve impacts on coverage and equity.

\subsection{Limitations}

As only papers written in English were included, other sources that may have been relevant may have been missed. In addition, due to financial resources and time, only papers that were available through the University of Toronto libraries were included. Nevertheless, the scoping review was sufficient to indicate the state of evidence available.

\section{Conclusions}

Our scoping review has identified the nature of literature on global health innovators and their organizations, funders, and educators relevant to training, mentorship and support of innovation in global health. It applied our findings to one programme aiming for Integrated Innovation ${ }^{\mathrm{TM}}$ in GCC's Stars in Global Health. More rigorous research and evaluation is needed to determine better processes for programmes to train, mentor and support innovators in global health and their effectiveness in impacting on global health equity.

\section{References}

Al-Bader, S., Frew, S. E., Essajee, I., Liu, V. Y., Daar, A. S., \& Singer, P. A. (2009). Small but tenacious: South Africa's health biotech sector. Nature Biotechnology, 27(5), 427-445. http://dx.doi.org/10.1038/nbt0509-427

Al-Bader, S., Masum, H., Simiyu, K., Daar, A. S., \& Singer, P. A. (2010a). Science-based health innovation in sub-Saharan Africa. BMC International Health and Human Rights, $10($ Suppl 1). http://dx.doi.org/10.1186/1472-698X-10-S1-S1

Al-Bader, S., Daar, A. S., \& Singer, P. A. (2010b). Science-based health innovation in Ghana: Health entrepreneurs point the way to a new development path. BMC International Health and Human Rights, 10(1). http://dx.doi.org/10.1186/1472-698X-10-S1-S2

Allen, L. K., Hetherington, E., Manyama, M., Hatfield, J. M., \& van Marle, G. (2010). Using the social entrepreneurship approach to generate innovative and sustainable malaria diagnosis interventions in Tanzania. Malaria Journal, 9(1). http://dx.doi.org/10.1186/1475-2875-9-42

Arksey, H., \& O’Malley, L. (2005). Scoping studies: Towards a methodological framework. International Journal of Social Research Methodology, 8(1), 19-32. http://dx.doi.org/10.1080/1364557032000119616

Battams, S., Matlin, S. A., Jahn, A., \& Kickbusch, I. (2011). The case for Europe as a leader in research and innovation for global health. Retrieved from http://www.globalhealtheurope.org/images/stories/ghe/GHEResearchPaperFinalNov2011.pdf

Chakma, J., Masum, H., \& Singer, P. A. (2010). Can incubators work in Africa? Acorn Technologies and the entrepreneur-centric model. BMC International Health and Human Rights, 10(Supp11). http://dx.doi.org/10.1186/1472-698X-10-S1-S7

Cozzens, S. E., \& Kaplinsky, R. (2009). Innovation, poverty and inequality: Cause, coincidence or co-evaluation? In Bengt-Ake, Lundvall, K.L Joseph, Cristina Chaminade and Jan Vang. Handbook of Innovation Systems and Developing Countries: Building Domestic Capabilities in a Global Setting. Edward Elgar: Cheltenham, UK. 
Frew, S. E., Rezaie, R., Sammut, S. M., Ray, M., Daar, A. S., \& Singer, P. A. (2007). India's health biotech sector at a crossroads. Nature Biotechnology, 25(4), 403-17. http://dx.doi.org/10.1038/nbt0407-403

Frew, S. E., Sammut, S. M., Shore, A. F., Ramjist, J. K., Al-Bader, S., Rezaie, R., ... Singer, P. A. (2008). Chinese health biotech and the billion-patient market. Nature Biotechnology, 26(1), 37-53. http://dx.doi.org/10.1038/nbt0108-37

Gardner, C. A., Acharya, T., \& Yach, D. (2007). Technological and social innovation: A unifying new paradigm for global health. Health Affairs, 26(4), 1052-1061. http://dx.doi.org/10.1377/hlthaff.26.4.1052

Grand Challenges Canada. (2010). Integrated innovation. Retrieved from http://www.grandchallenges.ca/wp-content/uploads/integratedinnovation_EN.pdf

Hotez, P., Gupta, R., Mahoney, R., \& Poste, G. (2005). Incorporating appropriate technology into North American schools of public health. Revista Panamericana de Salud Pública, 19(2), 118-123. http://dx.doi.org/10.1590/S1020-49892006000200007

Jackson, V. A., Palepu, A., Szalacha, L., Caswell, C., Carr, P. L., \& Inui, T. (2003). "Having the right chemistry": A qualitative study of mentoring in academic medicine. Academic Medicine, 78(3), 328-334. http://dx.doi.org/10.1097/00001888-200303000-00020

Kamunyori, S., Al-Bader, S., Sewankambo, N., Singer, P. A., \& Daar, A. S. (2010). Science-based health innovation in Uganda: Creative strategies for applying research to development. BMC International Health and Human rights, 10(Suppl 1), S5. http://dx.doi.org/10.1186/1472-698X-10-S1-S5

Li, L. C., Grimshaw, J. M., Nielsen, C., Judd, M., Coyte, P. C., \& Graham, I. D. (2009). Use of communities of practice in business and health care sectors: A systematic review. Implementation Science, 4(27), 16. http://dx.doi.org/10.1186/1748-5908-4-27

Mahayosnand, P. P., \& Stigler, M. H. (1999). The need for mentoring in public health. American Journal of Public Health, 89(8), 1262. http://dx.doi.org/10.2105/AJPH.89.8.1262

Malinen, P., Hautala, V., Orava, M., \& Puhakainen, J. (2008). Proceedings from 2008 International Council for Small Business World Conference: From Science to Business - Business Development Laboratory as a Developer of Science-Based New Ventures. Halifax, Nova Scotia: ICSB World Conference.

Manabe, Y. C., Jacob, S. T., Thomas, D., Quinn, T. C., Ronald, A., Coutinho, A., ... Merry, C. (2009). Resurrecting the triple threat: Academic social responsibility in the context of global health researchers. Clinical Infectious Diseases, 40, 1420-22. http://dx.doi.org/10.1086/598199

Matlin, S. A. (2008). The scope and potential of innovation for health and health equity. Global Forum Update on Research for Health, 5, 13-20.

Markham, S. K. (2002). Moving technologies from lab to market. Research Technology Management, 45(6), $31-42$.

Mboya-Okeyo, T., Ridley, R. G., \& Nwaka, S. (2009). The African Network for Drugs and Diagnostics Innovation. The Lancet, 373(9674), 1507-1508. http://dx.doi.org/10.1016/S0140-6736(09)60838-2

McCannon, C. J., Berwick, D. M., \& Massoud, M. R. (2007). The science of large-scale change in global health. Journal of the American Medical Association, 298(16), 1937-39. http://dx.doi.org/10.1001/jama.298.16.1937

McGahan, A. M. (2012). Paradoxes of Innovation in Health and their Resolution in Embedded Innovation. Munk Monitor, 2(Fall), 14-17

Morel, C. M., Acharya, T., Broun, D., Dangi, A., Elias, C., Ganguly, N. K., ... Yun, M. (2005). Health innovation networks to help developing countries address neglected diseases. Science, 309(5733), 401. http://dx.doi.org/10.1126/science.1115538

National Institutes of Health Fogarty International Center. (2012). Framework Programs for Global Health Innovation. Retrieved from http://www.fic.nih.gov/programs/pages/framework-innovations.aspx

Nelson, B. D., Kasper, J., Hibberd, P. L., Thea, D. M., \& Herlihy, J. M. (2012). Developing a career in global health: Considerations for physicians-in-training and academic mentors. Journal of Graduate Medical Education, 4(3), 301-306. http://dx.doi/org/10.4300/JGME-D-11-00299.1

Nwaka, S., Ilunga, T. B., Da Silva, J. S., Rial Verde, E., Hackley, D., De Vré, R., ... Ridley, R. G. (2010). Developing ANDI: A novel approach to health product R\&D in Africa. PLoS Medicine, 7(6). 
http://dx.doi.org/10.1371/journal.pmed.1000293

Oden, M., Mirabal, Y., Epstein, M., \& Richards-Kortum, R. (2010). Engaging undergraduates to solve global health challenges: A new approach based on bioengineering design. Annals of Biomedical Engineering, 38(9), 3031-3041. http://dx.doi.org/10.1007/s10439-010-0036-0

Palamountain, K. M., Stewart, K. A., Krauss, A., Kelso, D., \& Diermeier, D. (2010). University leadership for innovation in global health and HIV/AIDS diagnostics. Global Public Health, 5(2, SI), 189-196. http://dx.doi.org/10.1080/17441690903456274

PATH. (2013). PATH: A catalyst for global health. Retrieved from http://www.path.org/about/index.php

Perampaladas, K., Masum, H., Kapoor, A., Shah, R., Daar, A. S., \& Singer, P. A. (2010). The road to commercialization in Africa: Lessons from developing the sickle-cell drug Niprisan. BMC International Health and Human Rights, 10(1). http://dx.doi.org/10.1186/1472-698X-10-S1-S11

Rabin, B. A., Brownson, R. C., Haire-Joshu, D., Kreuter, M. W., \& Weaver, N. L. (2008). A glossary for dissemination and implementation research in health. Journal of Public Health Management and Practice, 14(2), 117-123. DOI: 10.1097/01.PHH.0000311888.06252.bb

Rezaie, R., Frew, S. E., Sammut, S. M., Maliakkal, M. R., Daar, A. S., \& Singer, P. A. (2008). Brazilian health biotech--fostering crosstalk between public and private sectors. Nature Biotechnology, 26(6), 627-44. http://dx.doi.org/10.1038/nbt0608-627

Shah, R., Singer, P. A., \& Daar, A. S. (2010). Science-based health innovation in Tanzania: Bednets and a base for invention. BMC International Health and Human Rights, 10(Suppl 1), S4. http://dx.doi.org/10.1186/1472-698X-10-S1-S4

Shah, S. K., Nodell, B., Montano, S. M., Behrens, C., \& Zunt, J. R. (2011). Clinical research and global health: mentoring the next generation of health care students. Global Public Health, 6(3), 234-246. http://dx.doi.org/10.1080/17441692.2010.494248

Simiyu, K., Masum, H., Chakma, J., \& Singer, P. A. (2010a). Turning science into health solutions: KEMRI's challenges as Kenya's health product pathfinder. BMC International Health and Human Rights, 10(Suppl), S10. http://dx.doi.org/10.1186/1472-698X-10-S1-S10

Simiyu, K., Daar, A. S., Hughes, M., \& Singer, P. A. (2010b). Science-based health innovation in Rwanda: Unlocking the potential of a late bloomer. BMC International Health and Human Rights, 10(Suppl 1), S3. http://dx.doi.org/10.1186/1472-698X-10-S1-S3

University of Toronto. (2013). Faculty of Medicine Institute of Global Health Equity and Innovation. Retrieved from http://www.ghd-si.utoronto.ca/global-health-faculty-and-researchers/university-of-toronto-institute-for-glob al-health-equity-and-innovation/

Yamey, G. (2011). Scaling up global health interventions: a proposed framework for success. PLoS Medicine, 8(6). http://dx.doi.org/10.1371/journal.pmed.1001049

Yamey, G. (2012). What are the barriers to scaling up health interventions in low and middle income countries? A qualitative study of academic leaders in implementation science. Globalization and Health, 8(1), 11. http://dx.doi.org/10.1186/1744-8603-8-11

\section{Copyrights}

Copyright for this article is retained by the author(s), with first publication rights granted to the journal.

This is an open-access article distributed under the terms and conditions of the Creative Commons Attribution license (http://creativecommons.org/licenses/by/3.0/). 